\title{
PKM MEDIA PEMBELAJARAN DI PONDOK PESANTREN AN NAHL DARUNNAJAH 5 CIKEUSIK
}

\author{
Lasia Agustina1*, Yogi Wiratomo², Abdul Karim³ $^{3}$ \\ ${ }^{1}$ Progam Studi Pendidikan Matematika, Universitas Indraprasta PGRI Jakarta \\ ${ }^{2}$ Progam Studi Pendidikan Matematika, Universitas Indraprasta PGRI Jakarta \\ ${ }^{3}$ Progam Studi Pendidikan Matematika, Universitas Indraprasta PGRI Jakarta \\ Corresponding author : \\ E-mail :lasia.agustina@unindra.ac.id
}

Diterima 2 Juli 2019, Disetujui 18 Juli 2019

\begin{abstract}
ABSTRAK
Kegiatan PKM Media Pembelajaran di Pondok Pesantren An-Nahl Darunnajah 5 Cikeusik, Pandeglang ini bertujuan untuk menjadikan guru sebagai pendidik yang berkualitas dan membawa suasana menyenangkan, dapat mengoptimalkan belajar peserta didik meningkatkan motivasi peserta didik menjadi lebih tinggi, sehingga mempunyai rasa senang dalam mengikuti proses pembelajaran. Kegiatan ini diharapkan mampu memberikan gambaran bagi guru mengenai media pembelajaran untuk mengembangkan dan mengoptimalkan kemampuan softskill peserta didik dalam kegiatan pembelajaran di Pondok Pesantren An Nahl Darunnajah 5. Peserta dalam kegiatan pelatihan ini adalah seluruh pengajar di Pondok Pesantren An-Nahl Darunnajah 5. Metode yang digunakan untuk mencapai tujuan yang telah dirumuskan di atas adalah memberikan informasi dalam penerapan Media Pembelajaran dengan Kombinasi Camtasia Studio dan Comic Strip. Materi yang diberikan saat pelatihan memuat pengenalan, perancangan dan penerapan. Pelaksanaan kegiatan ini dilakukan dalam tiga tahap, yaitu tahap persiapan, pelaksanaan, dan evaluasi.
\end{abstract}

Kata kunci:Media Pembelajaran

\section{ABSTRACT}

PKM ActivitiesLearning Media at Pondok Pesantren An-Nahl Darunnajah 5, Cikeusik, Pandeglang, Aims to make teachers a quality educator, and bring a pleasant atmosphere, can optimise student learning to increase the motivation of learners to a higher level, so have the pleasure of following the learning process. This activity is expected to provide a description for teachers on the media of learning to develop and optimize the ability of the student softskills in the learning activities at Pondok Pesantren An Nahl Darunnajah 5. Participants in this training activities are all teachers in Pondok Pesantren An-Nahl Darunnajah 5. The method used to achieve the above-formulated objectives is to provide information in the implementation of the learning Media with a combination of Cooperative Learning. The materials provided during the training contained the introduction, design and implementation. The implementation of this activity is conducted in three phases, namely the preparation, implementation, and evaluation.

Keywords: Learning Media

\section{PENDAHULUAN}

Pengadaan pendidikan karakter dirasakan penting dikarenakan terjadi pergeseran nilai-nilai dan norma yang berlaku umum di masyarakat. Hal yang dahulu dianggap tabu, kini dianggap biasa bahkan tidak jarang yang mengikuti agar menjadi trend. Dengan adanya pendidikan karakter, diharapkan dapat mengurangi terjadinya pergeseran norma yang terjadi di masyarakat. Berbekal nilai karakter yang baik, peserta didik diharapkan memiliki wawasan, perilaku, dan sikap yang sesuai dengan norma yang berlaku di masyarakat. Secara tidak langsung, apabila karakter dari peserta didik baik, maka akan menunjang pengetahuan yang baik pula.

Salah satu yang memiliki peran penting dalam menunjang pembentukan karakter bagi peserta didik adalah di sekolah. Sekolah sebagai lembaga pendidikan formal menjadi salah satu keberhasilan pendidikan karakter, hal ini didukung oleh konsistensi dan kontinuitas pelaksanaan. Pada lingkungan sekolah, peserta didik tidak cukup hanya 
dikembangkan bidang akademik nya saja, namun harus juga diperhatikan aspek moral. Guru dalam hal ini merupakan pihak yang akan menuliskan karakter apapun yang akan dibentuk dalam lingkungan sekolah. Peran guru sangatlah penting dalam pelaksanaan pendidikan karakter terhadap siswa, karena berinteraksi langsung secara terus menerus dalam proses pembelajaran. Guru merupakan media secara langsung bagi siswa, oleh karena itu guru harus memiliki sikap-sikap sebagai pendidik karakter.

Pendidikan karakter sebenarnya sangat penting diterappkan dalam proses pembelajaran. Namun, apa yang diharapkan pemerintah dibidang pendidikan belum berjalan semestinya. Hal ini disebabkan oleh beberapa hal, antara lain: Pertama, kurang terampilnya para guru menyelipkan pendidikan karakter dalam proses pembelajaran. Kedua, sekolah terlalu fokus mengejar target-target akademis, khususnya target lulus ujian nasional (UN). Ketiga, banyaknya stakeholder pendidikan belum mampu memberikan contoh teladan terhadap anak didik. Keempat, era globalisasi yang sangat pesat menggemparkan membawa tantangan serius bagi dunia pendidikan (Sukri, 2013). Berbagai penyebab tersebut membawa pengaruh yang tidak baik bagi hasil pembelajaran peserta didik.

Masalah pokok yang akan dipecahkan dalam pengabdian masyarakat ini berkaitan dengan masih minimnya informasi mengenai media pembelajaran untuk mengembangkan dan mengoptimalkan kemampuan softskill peserta didik dalam kegiatan pembelajaran di Pondok Pesantren An Nahl Darunnajah 5. Oleh karena itu, diperlukan berbagai media pembelajaran yang tepat dan relevan, salah satunya adalah media kombinasi pembelajaran kooperatif dengan pendekatan camtasia studio.

Untuk mengatasi permasalahan yang dihadapi oleh mitra yaitu Pondok Pesantren An-Nahl Darunnajah 5 Cikeusik, maka solusi yang ditawarkan antara lain: a) pelatihan media pembelajaran dengan kombinasi camtasia studio untuk membangkitkan minat peserta didik b) Memfasilitasi kesempatan untuk meningkatkan inovasi pembelajaran guru dalam proses pembelajaran. Target lain yaitu tersedianya perangkat pembelajaran media pembelajaran dengan kombinasi camtasia studio yang sudah disusun oleh guru.

\section{METODE}

Metode yang digunakan untuk mencapai tujuan yang telah dirumuskan di atas adalah memberikan informasi dalam penerapan Media Pembelajaran dengan
Kombinasi Camtasia Studio. Materi yang diberikan saat workshop memuat pengenalan, perancangan dan penerapan. Pelaksanaan kegiatan ini dilakukan dalam tiga tahap, yaitu tahap persiapan, pelaksanaan, dan evaluasi. Tahap pertama adalah tahap persiapan. Dalam tahap ini tim melakukan survei pendahuluan untuk mengetahui kondisi target kegiatan dengan menganalisis kondisi tempat yang akan digunakan, kondisi peserta yang akan diberikan pelatihan, dan menyusun rancangan kegiatan yang akan dilakukan. Tahap kedua yaitu tahap pelaksanaan. Tim melakukan pelatihan Media Pembelajaran dengan Kombinasi Camtasia studio sebagai Strategi Menjadikan Sekolah Berkarakter yang ditujukan untuk seluruh perangkat Pondok Pesantren An Nahl Darunnajah 5. Tahap ketiga adalah evaluasi. Evaluasi kegiatan ini dilakukan terhadap proses kegiatan. Evaluasi berkaitan selama kegiatan berlangsung dari tahap persiapan sampai tahap pelaksanaan, yang meliputi keadaan sekolah, kehadiran peserta pelatihan, antusias peserta saat mengikuti kegiatan, dan saran atau kritik terhadap kegiatan.

Waktu pelaksanaan kegiatan selama bulan Maret hingga Agustus tahun 2019, mulai dari observasi daerah mitra hingga pembuatan laporan. Kegiatan pelatihan ini akan dilaksanakan di Pondok Pesantren An Nahl Darunnajah 5, yang beralamat di Jl. Cikareo Mantiung, Ciseureuh, Tanjungan, Pandeglang, Banten, Jawa Barat. Kegiatan ini akan dilaksanakan pada bulan Mei 2019. Adapun partisipasi mitra dalam hal ini adalah pihak Pondok Pesantren An-Nahl Darunnajah 5 dalam kegiatan pengabdian kepada masyarakat antara lain: 1) Partisipasi dalam perencanaan dan pengambilan keputusan.; 2) Partisipasi dalam pelaksanaan, meliputi: penyediaan tempat, kegiatan administrasi, koordinasi dan penjabaran program. Partisipasi dalam pelaksanaan merupakan kelanjutan dalam rencana yang telah digagas sebelumnya baik yang berkaitan dengan perencanaan, pelaksanaan maupun tujuan.; 3) Partisipasi dalam evaluasi. Partipasi dalam evaluasi ini berkaitan dengan pelaksanaan program yang sudah direncanakan sebelumnya.

\section{HASIL DAN PEMBAHASAN Hasil}

Sesuai dengan skema yang sudah direncanakan oleh tim abdimas, pelaksanaan kegiatan ini dilakukan dalam tiga tahap, yaitu tahap persiapan, pelaksanaan, dan evaluasi. Realisasi pelaksanaan sesuai dengan 
perencanaan tim pelaksana. Pada tahap persiapan, tim pelaksana meninjau lokasi mitra yaitu Pondok Pesantren An-Nahl Darunnajah 5. Pondok Pesantren An Nahl Adalah Salah Satu Cabang Pesantren Darunnajah Jakarta yang ke 5 dengan Luas areal 2 hektar. Pondok Pesantren An Nahl didirikan Pada tanggal 18 Juli 2004 yang tempatnya berada di ujung barat pulau Jawa, tepatnya di Kampung Ciseureuh Desa Tanjungan Kecamatan Cikeusik Kabupaten Pandeglang Provinsi Banten.

Pondok pesantren Darunnajah 5 AnNahl terdiri dari Madrasah Aliyah, Madrasah Tsanawiyah dan Madrasah Ibtidaiyah. Visi dari Ponpes ini adalah menuju pesantren mandiri sebagai sentral pembinaan generasi tafaqquhfiddin dan kaderasasi pemimpin umat. Dalam kegiatan survey lokasi objek penelitian ini dilakukan diskusi dengan pimpinan pesantren, kepala sekolah dan beberapa guru untuk mengetahui permasalahan mitra yang terjadi. Dari hasil diskusi tersebut, didapatkan bahwa permasalahan yang dihadapi guru adalah: 1) Guru masih merasa kesulitan dalam mengintegrasikan pendidikan karakter dalam proses pembelajaran, 2) Sekolah masih terlalu fokus pada aspek kognitif (pengetahuan), 3) tuntutan di Era industri 4.0 dimana teknologi yang sangat pesat tantangan serius bagi dunia pendidikan dan mempengaruhi karakter peserta didik.

Berdasarkan masalah tersebut, tim pengabdian dan pihak pondok pesantren sepakat mengadakan kegiatan pengabdian masyarakat untuk meningkatkan kompetensi guru melalui pelatihan yang bertujuan menjadikan guru sebagai pendidik yang berkualitas dan membawa suasana menyenangkan di setiap proses pembelajaran. Adapun pelatihan yang diberikan meliputi materi : media Pembelajaran Kooperatif dengan bantuan Camtasia studio, dan pemberian motivasi kepada guru di lingkungan pondok pesantren An-Nahl 5 Darunnajah. Sesuai dengan kesepakatan yang dilakukan antara tim abdimas dan pihak pondok pesantren, maka pelaksanaan kegiatan abdimas dilakukan pada selama dua hari.

Pada hari pertama, pukul 07.00 tim berkumpul di Kampus A Universitas Indraprasta PGRI untuk menuju lokasi pengabdian. Karena jarak tempuh yang cukup jauh, maka tim sudah menyiapkan segala perbekalan selama dalam perjalanan. Tim tiba di lokasi pada pukul 16.00. Tim diarahkan untuk beristirahat di tempat yang sudah disediakan oleh pihak pondok pesantren. Setelah sholat isya, tim dan pihak pondok pesantren yang diwakili oleh pimpinan pondok dan salah satu pengajar Pondok yaitu mendiskusikan mengenai persiapan pelaksanaan kegiatan abdimas yang akan dilaksanakan esok hari.

Keesokan hari, kegiatan dimulai pukul 08.00 dengan pemberian sambutan yang disampaikan oleh Pimpinan pondok pesantren An-Nahl 5 Darunnajah, Cikeusik, Pandeglang, Banten, sekaligus membuka kegiatan Pengabdian Kepada Masyarakat. Berikutnya adalah sambutan dari Ketua Tim Pelaksana Abdimas. Peserta kegiatan terdiri dari seluruh pengajar di lingkungan Pondok Pesantren AnNahl 5 Darunnajah, Cikeusik, Pandeglang.Pemberian materi dimulai pukul 08.30 mengenai pengenalan Camtasia studio yang disampaikan oleh Yogi Wiratomo, M.Pd. Guru dipandu untuk meninstall aplikasi software camtasia studio di laptop masingmasing. Sesudah seluruh guru berhasil menginstal, tim memberikan tutorial dan penjelasan penggunaan camtasia studio. Seluruh guru terlihat antusias mengikuti materi dan tidak segan bertanya kepada tim jika ada yang kurang dipahami.

Guru dituntut aktif agar dapat menumbuhkan kreatifitas peserta didik sehingga aktif dalam pembelajaran. Contohnya dengan menampilkan permasalahan sehari-hari yang terjadi di lingkungan sekitar.

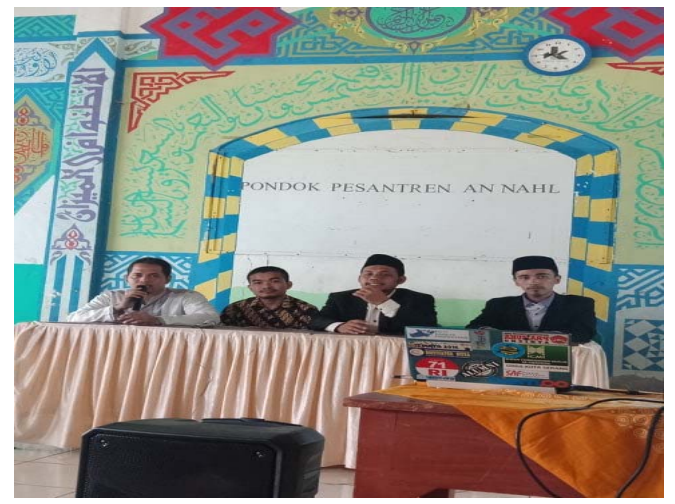

Gambar 1. Penyampaian materi PKM

Peserta tertarik dan antusias dengan materi yang disampaikan oleh tim, terlihat dengan keaktifan dalam bertanya. Salah satu peserta menanyakan kondisi yang terjadi sehari-hari di kelas mengenai bagaimana untuk membuat materi yang akan disampaikan ke peserta didik menjadi lebih menarik dengan media Camtasia Studio. Tim memberikan solusi bahwa dengan menggunakan media pembelajaran berbantuan Camtasia Studio ini 
maka peserta didik akan lebih tertarik dengan adanya animasi gambar, suara dan vidio disetiap media pembelajaran berbantuan Camtasia Studio, namun sebelumnya guru harus sudah menguasi cara penggunaan media berbantuan Camtasia Studio. Pertanyaan selanjutnya ialah langkah-langkah yang harus dilakukan agar suatu materi yang akan disampaikan pada siswa dengan media berbantuan Camtasia Studio dapat tersampaikan dengan baik dan benar. Tim memberikan solusi yaitu guru merancang terlebih dahulu materi apa yang akan dibuat dengan bantuan Camtasia studio, lalu buatlah animasi baik dengan gambar, suara ataupun vidio sehigga menghasilkan suatu media pembelajaran yang menarik bagi siswa.

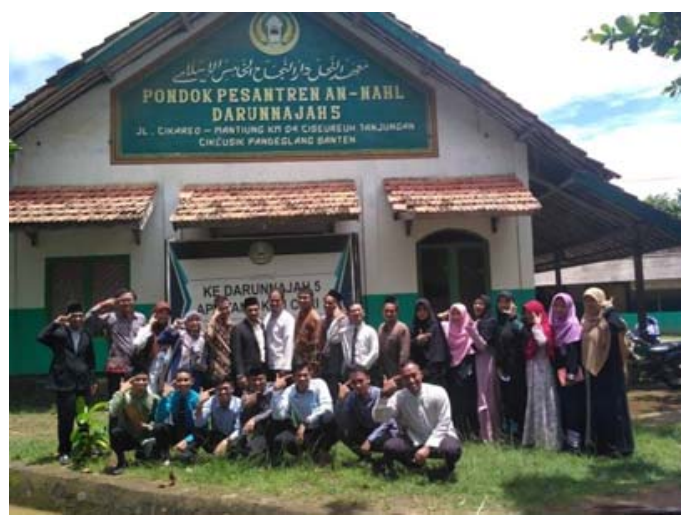

Gambar 2. Tim beserta para peserta kegiatan abdimas

Pelatihan dilanjutkan kembali pada pukul 13.30 setelah tim dan peserta melakukan istirahat makan siang dan solat zuhur. Materi yangdisampaikan mengenai simulasi pebuatan media pembelajaran berbantuan camtasia studio, Setelah materi disampaikan, guru dipersilahkan untuk mencoba membuat rancangan materi yang disajikan dengan menggunakan materi pembelajaran camtasia studio yang akan dilakukan dengan didampingi oleh tim abdimas. Materi ini selesai hingga pukul 15.00 dan ditutup kembali oleh Pimpinan Pondok.

\section{Pembahasan}

Camtasia adalah software (perangkat lunak) yang dikembangkan oleh TechSmith Coorporation. Camtasia ini sendiri digunakan untuk merekam semua aktivitas yang ada pada desktop komputer. Software ini bisa kita manfaatkan untuk membuat media pembelajaran berbasis multimedia dan $e$ learning. Camtasia adalah suatu perangkat lunak yang bisa merekam aktivitas yang ada pada desktop komputer.Camtasia studio merupakan aplikasi utama dari Camtasia Corporation. Didalamnya terdapat semua fungsi utama Camtasia Studio Application ( camtasia recorder, camtasia menu maker, camtasia theater) selain itu juga terdapat menu timeline untuk mengedit video, memberikan transisi, title (judul), sound, kuis, sampai mengekspor video

Adapun Menu-menu yang terdapat pada camtasia studio 8 , antara lain: menu File yang berisi:a. New Project : Membuat lembaran project baru; b. Open Project : Membuka project yang sudah pernah dibuat; c. Recent Project/Recording : Project/recording yang pernah dibuat sebelumnya; d. Save Project : Menyimpan project; e. Save as Project : Menyimpan project dengan nama lain; f. Record camera : Merekam layar untuk membuat tutorial; g. Impor media : Mengimpor media yang sudah jadi untuk proses pengeditan. Menu Edit, berisi: a. Undo : Membatalkan proses/perintah proses; b. Redo : Mengembalikan proses yang pernah dibatalkan; c. Add to timeline : Menambahkan media pada timeline untuk proses edit; $d$. Cut selection : Memotong video; Menu View: a. Story board : Tampilan dalam bentuk story board (untuk meyisipkan Transitions); Timeline : Untuk mengedit project anda seperti memotong klip, menambahkan, mengedit sound dsb;b. Full screen : Memperbesar tampilan penuh;c. Zoom in : Memperbesar tampilan;d. Zoom out : Memperkecil tampilan.

Dalam Camtasia 8 ini memiliki beberapa aplikasi antara lain:Camtasia recorder, dimana Camatasia recorder adalah sebuah komponen screen recording sederhana yang powerfull untuk mengcapture pergerakan kursor. Dengan fitur camtasia studio recorder, anda dapat : a) Merekam semua atau beberapa bagian pada layar (screen) seperti menekan mouse dan tombol, b) Merekam suara pada microfon dan aplikasi audio seperti efek suara, menekan mouse, mengetik dengan keyboard; c) Menggambar dan highlight pada screen dengan menggunakan screen pada; d) Merekam keterangan gambar pada ScreenDraw, menggunakan hotkeys untuk memperkecil (zoom out) dan memperbesar (zoom in) 


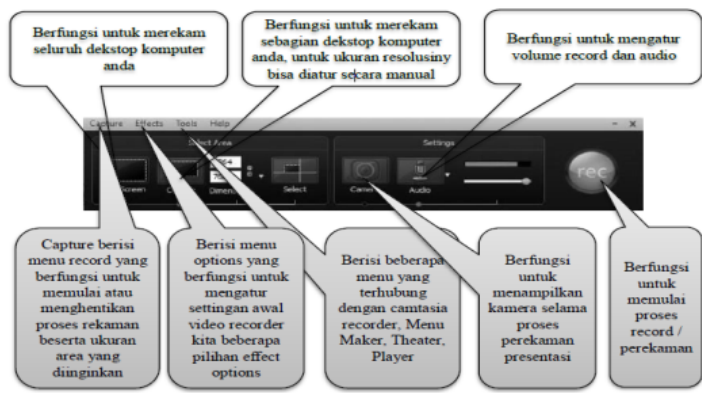

Gambar 3. Camtasia recorder.

Seluruh guru terlihat antusias saat pelatihan berlansung. Hal ini dikarenakan camtasia studio adalah sesuatu yang baru untuk guru. Awalnya beberapa guru merasa kesulitan dalam menjalankan aplikasi tersebut. Namun dengan bimbingan dan arahan tim abdimas, sedikit demi sedikit guru mengerti bagaimana menggunakan media pembelajaran camtasia studio. Beberapa dari guru juga antusias bertanya jika kurang mengerti. Secara keseluruhan, kegiatan pengabdian kepada masyarakat dengan tema workshop media pembelajaran camtasia studio berjalan dengan lancar.

\section{SIMPULAN DAN SARAN}

Secara keseluruhan kegiatan pengabdian masyarakat ini dirasa telah memberi kontribusi positif sebagai upaya untuk menciptakan guru sebagai pendidikan yang berkualitas dan membawa suasana menyenangkan di setiap proses pembelajaran. Kegiatan ini telah berjalan dengan baik dan dapat disimpulkan sebagai berikut: 1. Materi media pembelajaran berbasis IT camtasia studio bertujuan untuk mengoptimalkan belajar peserta didik dan meningkatkan motivasi peserta didik menjadi lebih tinggi, sehingga mempunyai rasa senang dalam mengikuti proses pembelajaran. 2. Guru antusias dalam pelaksanaan kegiatan dan mulai termotivasi untuk menghadirkan kegiatan pembelajaran aktif, inovatif, kreatif, edukatif dan menyenangkan (PAIKEM) di kelas.

Dari simpulan, maka kami mengajukan saran dan rekomendasi sebagai berikut: 1.Guru harus selalu meningkatkan keaktifan dan motivasi belajar matematika siswa agar hasil belajar yang didapatkan sesuai dengan kompetensi yang ingin dicapai. 2.Guru hendaknya menerapakan model pembelajaran yang inovatif dan menggunakan strategi, model dan media pembelajaran yang mudah dibuat agar pembelajaran lebih menyenangkan bagi siswa. 3.Pihak terkait seperti Dinas Pendidikan perlu memberikan perhatian khusus dalam upaya meningkatkan kualitas pembelajaran matematika. 4.Kegiatan pelatihan yang serupa perlu dilaksanakan secara berkesinambungan, intensif dengan melibatkan lebih banyak peserta dan pihak terkait seperti Dinas Pendidikan, LPMP, Perguruan Tinggi secara kolaboratif.

\section{DAFTAR RUJUKAN}

Mulyasa, E. 2007. Menjadi Guru Profesional Menciptakan Pembelajaran Kreatif dan Menyenangkan. Bandung : Remaja Rosddakarya.

Sukri. 2013. Implementasi Pendidikan Karakter di Sekolah Menengah Pertama Islam Terpadu (SMPIT) Darul Azhar Aceh Tenggara. Tesis. IAIN Sumatera Utara.

Watson, M. (2008). Developmental discipline and moral education. Dalam Nucci, LP., \& Narvaez, D. (Penyunting). Handbook of moral and character. New York: Routledge.

https://ch3quit4.wordpress.com/2011/11/17/ap a-itu-program-camtasia-studio/

http://id.wikihow.com/Menggunakan-Camtasia 